\title{
Cyclic lateral behavior of friction stir spot welds of AA2219 aluminum alloy: impact of inherent flow defects
}

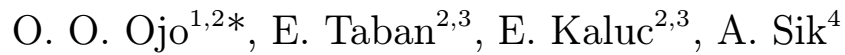 \\ ${ }^{1}$ The Federal University of Technology Akure, Ondo State, Nigeria \\ ${ }^{2}$ Kocaeli University, Kocaeli, Izmit, Turkey \\ ${ }^{3}$ Welding Research Education and Training Centre, Kocaeli University, Izmit, Turkey \\ ${ }^{4}$ Gazi University, Ankara, Turkey
}

Received 12 January 2019, received in revised form 18 May 2019, accepted 20 May 2019

\begin{abstract}
Structural damage and fatigue life of engineering materials are controlled by inherent defects and the nature, level, and location of applied external loads. This paper studies the effect of cyclic lateral loads on the pinless and conical-pin assisted friction stir spot welds of AA2219 alloy. The results reveal the presence of upward-flow induced hook defect and outstretchingflow induced microscopic toe-notch in the conical pin and pinless welds, respectively. Extruded flash root contributed to the fracture pattern of the conical pin welds while it did not influence the fracture of the pinless weld. Grain refinement, microhardness, and microscopic toe-notch affect the fracture mode of pinless weld whereas complex fracture morphology ensues in conical pin weld. A decrease in the cyclic lateral stress level improves the lateral fatigue lives of both weld categories. Lateral fatigue improvement of welds requires the minimization of inherent nugget defects and extruded flash.
\end{abstract}

K e y w or d s: friction stir spot welding, cyclic lateral behavior, fatigue, pinless weld, conical pin weld, fracture

\section{Introduction}

Friction stir (spot) welding is a novel solid-state joining process (pioneered by The Welding Institute in the 1990s) that has become a suitable substitute for conventional fusion welding processes by eliminating improper solidification and intrinsic liquation cracking, weld discontinuities (micro- and macro-pores, and inclusions), and distortion due to high heat input [14]. Friction stir (spot) welding has found a broad application in offshore construction (orbital welding of pipelines), automotive, high-speed train manufacturing, shipbuilding, and aerospace industries $[5,6]$. High strength-to-weight ratio, excellent corrosion resistance of aluminum alloys, and derived benefits from aluminum-based engineering systems such as fuel economy, better performance, and reduced greenhouse gas emissions [7-10] have made aluminum alloys important structural materials in the transportation industries. The necessity of aluminum alloys for mod- ern manufacturing has consequently opened up research areas toward the identification of efficient aluminum welding process and the likely in-service behavior of aluminum welds. Fatigue behavior of aluminum weld is a critical research area that is primarily needed to predict and mitigate failures or to ascertain structural integrity [11] in vital industries such as aerospace, high-speed train, and automotive industries.

About $50-90 \%$ of structural and mechanical assembly's in-service failures have been attributed to fatigue failures [12]. Welds or joints are often predominantly sensitive to fatigue loads due to their inherent residual stress level [13], microstructural variations, and the presence of inclusions and blowholes (micro or coarse pores). Das et al. [14] and Uematsu et al. [15] reported that microstructural features (SZ - stir zone, TMAZ - thermomechanical affected zone, and HAZ - heat affected zone) and energy input affect the fatigue strength of friction stir welded $\mathrm{Al}$ alloys. The low

*Corresponding author: e-mail address: ojooladimeji90@yahoo.com 
Table 1. Chemical composition of AA2219 aluminum alloy (wt.\%)

\begin{tabular}{cccccccccccccc}
\hline Alloy & $\mathrm{Al}$ & $\mathrm{Si}$ & $\mathrm{Fe}$ & $\mathrm{Cu}$ & $\mathrm{Mn}$ & $\mathrm{Mg}$ & $\mathrm{Cr}$ & $\mathrm{Zn}$ & $\mathrm{Ti}$ & $\mathrm{V}$ & $\mathrm{Zr}$ & $\mathrm{Other}$ \\
\hline 2219 & $\mathrm{Bal}$ & 0.06 & 0.14 & 6.6 & 0.32 & 0.02 & 0.00 & 0.03 & 0.04 & 0.06 & 0.13 & 0.03 & \\
\hline
\end{tabular}

heat input of friction stir spot welding (FSSW) process inhibits weld's distortion [16] and residual stress to a comparatively low fraction of the weld's proof strength. This attribute is beneficial for the dynamic loading behavior of welds placed-in-service [12]. Friction stir welding is an effective approach to obtain stable ultrafine-grained microstructures. Howbeit, most of the friction stir spot welded components used in the aerospace, aviation, and automotive industries are subjected to fatigue loads [17]. The assessment of fatigue behavior of friction stir spot welds under different dynamic loading patterns is thus considered critical.

It has been reported that failure modes of spot weld under quasi-static and cyclic loading conditions are quite different [18-20]. The applied stress or load on friction stir spot welds affects fatigue crack growth/path and fatigue strength of welds. For instance, the plug type fracture through the upper plate reduced fatigue strength at high applied loading conditions in re-filled spot welds [21]. The microstructural properties of welds, loading conditions, and distribution of localized cyclic plastic deformation influence crack initiation and propagation during dynamic loading of weld samples [22]. For example, cracks may form at matrix-inclusion interfaces, assisted by matrix strain localization associated with interfacial debonding or particle fracture [22].

Most of the available studies in the literature show that the axial dynamic/cyclic loading of aluminum friction stir spot welds has been investigated [9]. Venukumar et al. [17] examined the failure modes and fatigue behavior of axial loaded refilled and conventional friction stir spot welds of AA6061-T6 alloy. The paths of the dominant fatigue cracks were analyzed, and it was affirmed that crack initiation ensued near the unwelded joint interface [17]. Lin et al. [18, 23 studied the failure modes and fatigue life estimations of the friction stir spot welds of 6111-T4 and 6061-T6 Al alloys, respectively. Kinked fatigue crack growth in the lower plate outside of the weld stir zone was affirmed to be the dominant fatigue crack responsible for the weld's final failure [18]. Su et al. [24], Wang et al. [25], and Lin et al. [23] utilized fatigue crack models based on the Paris law and local stress intensity factors in predicting fatigue lives of friction stir spot welds. Equally, Tran et al. [20] also worked on kinked fatigue crack model based on the stress intensity factor. However, the result of the experimental observation provided by Wang et al. [25] revealed that fatigue cracks grew along the circumference of the weld nugget and propagated through the sheet thickness; consequently, the propagation of a crack in the width direction led to the weld's ultimate failure [25]. Fatigue behaviors of dissimilar aluminum alloy/steel friction stir spot welds have been examined [26, 27]. Stress relaxation at the nugget edge facilitated better fatigue performance in aluminum/galvanized steel welds [27].

Tool profile influences material flow, expelled flash properties, bonded/nugget size, and mechanical properties of welds [28-31]. There is a need to examine the influence of welding tools on fatigue strength. Despite the numerous technical papers on fatigue behavior of materials, there is still a paucity of data on lateral fatigue behavior of friction stir spot welds. In this research work, attention is solely focused on the lateral fatigue behavior of friction stir spot welds of AA2219 $\mathrm{Al}$ alloy produced with different tool morphologies. A critical look into the impact of inherent flow defects on cyclic lateral loading of the joints was studied. The fracture surfaces of the failed specimens were analyzed via the use of a scanning electron microscope while the influences of microstructure and microhardness values on the fatigue failure were also examined.

\section{Materials and method}

The research was carried out with $1.6 \mathrm{~mm}$ thick rolled AA2219 Al alloy sheets. The chemical composition of the alloy is provided in Table 1 . The ultimate tensile strength and yield strength of the alloy are 146 and $63 \mathrm{MPa}$, respectively. The as-received alloy was cut and cleaned with acetone before the commencement of the friction stir spot welding (FSSW) process. The cut lap shear specimen of the alloy consisted of two pieces of $100 \mathrm{~mm} \times 30 \mathrm{~mm} \times 1.6 \mathrm{~mm}$ sheet which were positioned in an overlapped configuration with an overlapped area of $30 \mathrm{~mm} \times 30 \mathrm{~mm}$. Pinless and conical pin tools were fabricated from high-speed steel (HSS) tool material, and these tools were employed for the welding process. The shoulder diameter of the pinless tool was $10 \mathrm{~mm}$ while the conical pin tool had shoulder diameter, pin height, pin base diameter, and a pin tip diameter of $10,2.47,6$, and $3 \mathrm{~mm}$, respectively (see Fig. 1). The welding parameters employed for the study are shown in Table 2 . These parameters were selected based on the outcome of the preliminary experiment of high and low tensile strength. 
Ta ble 2. Welding parameters employed for the study

\begin{tabular}{llccc}
\hline \multirow{2}{*}{ Weld codes } & Weld description & \multicolumn{3}{c}{ Welding parameters } \\
\cline { 3 - 5 } & & Tool rotation speed (rpm) & Shoulder plunge depth (mm) & Dwell time (s) \\
\hline FAT1 & Conical pin weld & 1400 & 0.43 & 4 \\
FAT8 & Conical pin weld & 1600 & 0.45 & 4 \\
P-FAT3 & Pinless weld & 1400 & 0.80 & 8 \\
P-FAT7 & Pinless weld & 1600 & 0.43 & 8 \\
\hline
\end{tabular}

(a)

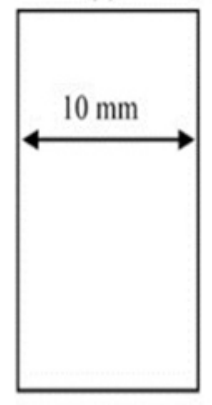

(b)

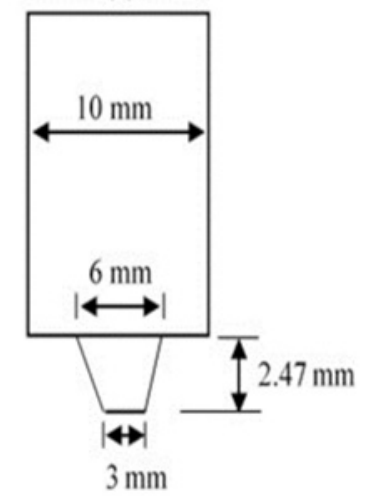

Fig. 1. Schematic illustrations of tool profile: (a) pinless tool and (b) conical pin tool.

To efficiently understand the fracture morphology of welds subjected to bending cyclic loading conditions, the microstructure and hardness of welds need to be examined. The cross sections of welds were obtained, ground, and finished with diamond pastes in an electropolishing unit. The weld cross sections were etched in $2 \%$ tetrafluoroboric acid to reveal the weld microstructures. The prepared metallographic samples were examined under ZEISS light optical microscope $(\mathrm{OM})$ while the microhardness distribution across the weld sections was determined through the application of Vickers microhardness technique (on Shimadzu DUH-211 hardness tester) by using $500 \mathrm{~g}$ load and $10 \mathrm{~s}$ dwell time.

The fatigue specimens were machined from the lap shear specimens of the alloy according to DIN 50100 standards as illustrated in Fig. 2. The specimen was mounted vertically on the fatigue testing machine in a manner perpendicular to the loading direction of the machine, as shown in Fig. 3. Before the fatigue testing, the machined curvature (region) of the fatigue specimens was ground with emery papers and finished/polished with finer emery papers to remove cutting induced flash/blur and tool marks, and to create a reflective or smoother outlook. All fatigue samples were subjected to wholly reversed or fully cyclic bending (lateral) loading conditions $(R=-1)$ at room tem-
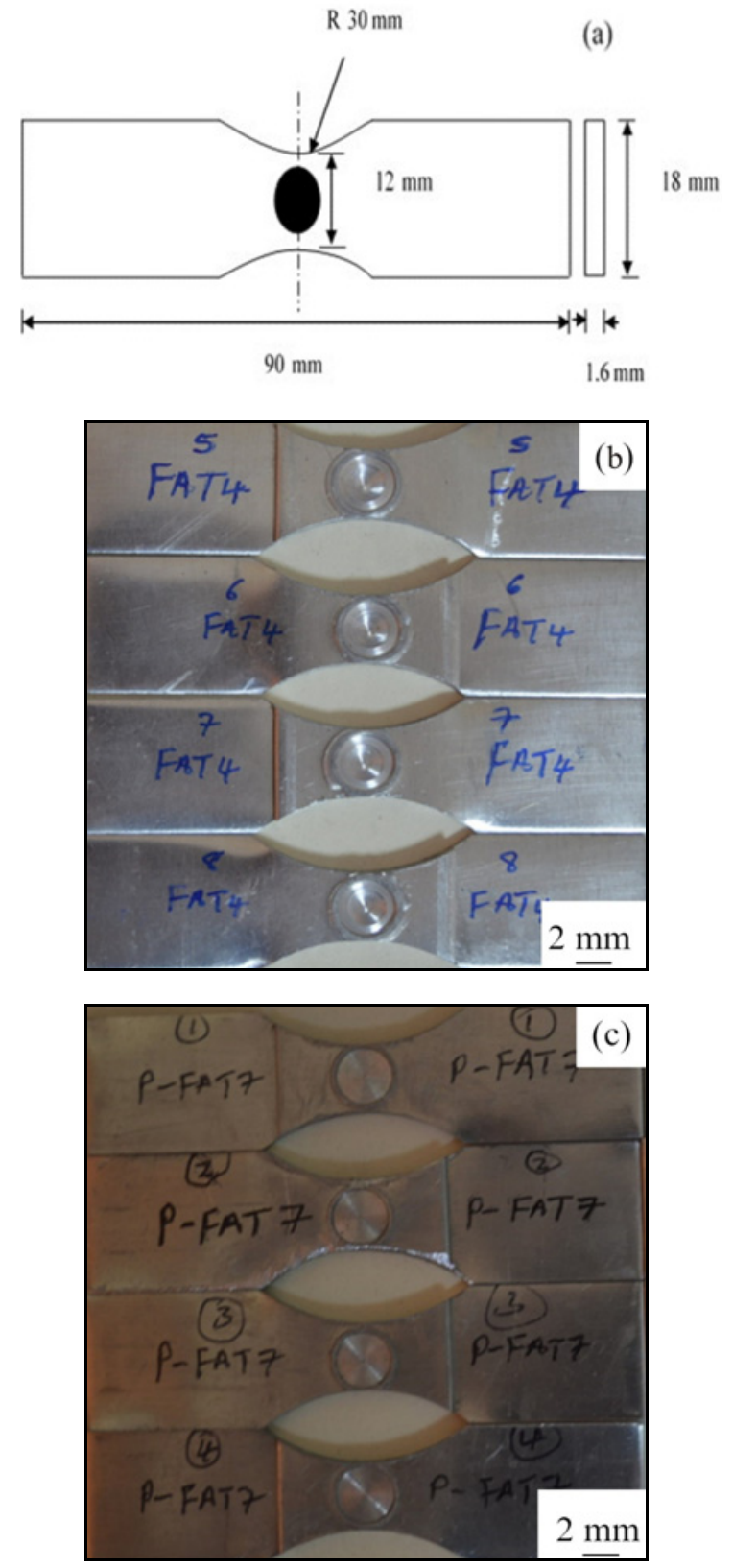

Fig. 2. Fatigue specimen: (a) schematic illustration showing all dimensions, (b) fabricated conical pin welded fatigue specimens, and (c) fabricated pinless welded fatigue specimens. 


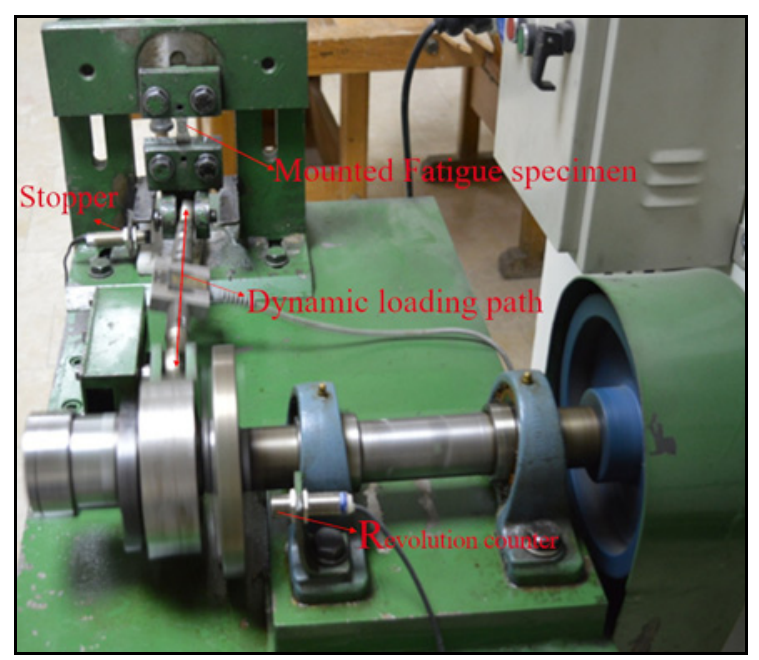

Fig. 3. Bending fatigue testing of the FSSW'ed specimen with an electrical-controlled bending fatigue machine.

perature on an electrically controlled bending fatigue machine. The specimens were loaded until complete failure was obtained; this was the stopping criterion adopted for each fatigue test. The fracture surfaces of welds subjected to bending dynamic lateral loading conditions were examined in a Jeol JSM-7900F scanning electron microscopy (SEM).

\section{Results and discussion}

\subsection{Microstructure of joints}

Hook defects are revealed in the micrographs of the conical pin welds whereas induced microscopic toenotch is present in the shallow cavity (around the bottom edge) of the pinless welds as shown in Fig. 4.

The hook defect is attributed to the upward material flow around the pin periphery in the conical pin welds (the tool penetration action into the bottom sheet enforces upward material flow to form the hook profile) [32-36]. On the other hand, the material flow underneath the shoulder surface towards the shoulder edge in the pinless welds is responsible for the microscopic toe-notch defect in the pinless weld. Evidence of the circumferential flow of the plasticized material is revealed in Fig. 5. According to Oladimeji et al. [28], this flow enforces the circumferential drag of the severely plasticized material towards the shoulder edge for expulsion as a flash. Such lateral flow beneath the shoulder surface is adjudged to have created a large centrifugal drag force responsible for the microscopic toe-notch observed in Fig. 4a. It has been reported that weld defects (such as toe-flash, kissing bond and excessive tool depth) are responsible for a shift in failure load and fatigue performance in the
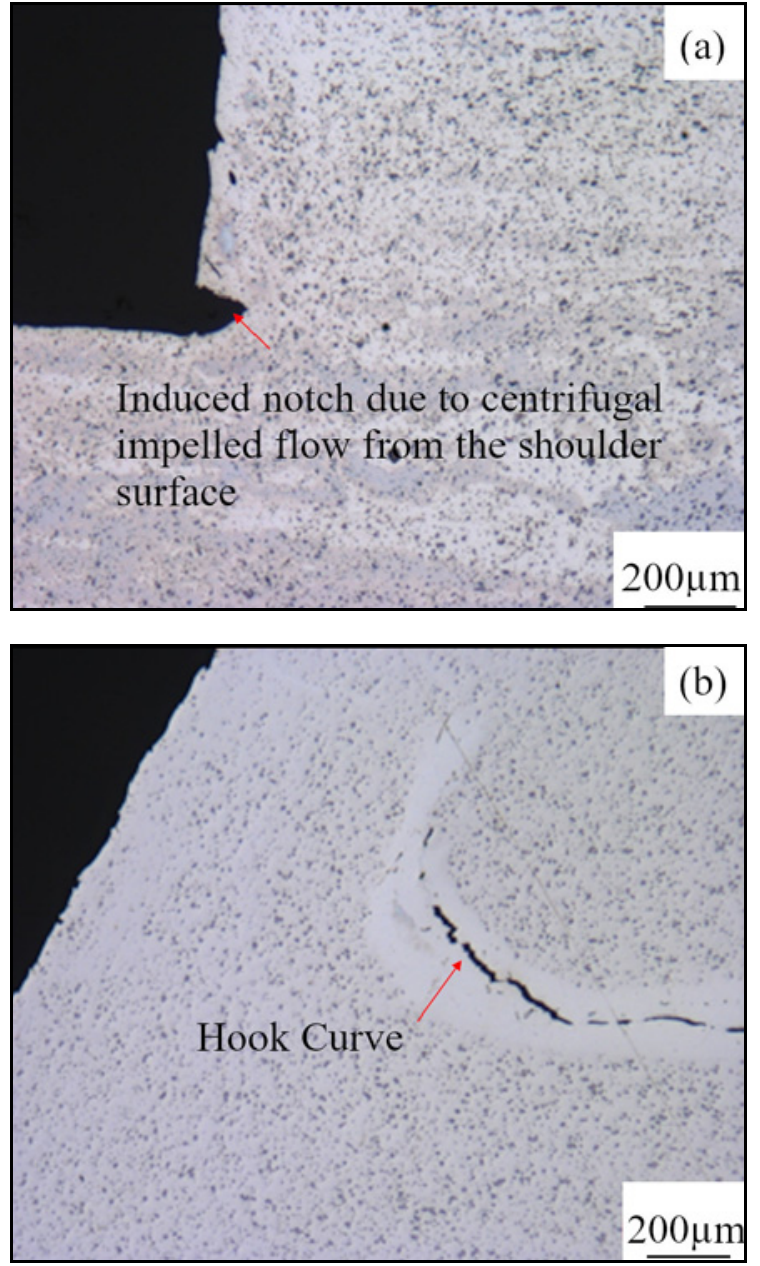

Fig. 4. Micrographs showing weld defects: (a) pinless weld (P-FAT3) and (b) conical pin weld (FAT1).

works of Guo et al. [37]. Literature also has it that kissing bond impairs fatigue life while toe-flash defect has less effect on fatigue life [37]. The effects of the observed notable defects on the fatigue strength and the fracture of the welded joint are thus studied in Sections 3.3 and 3.4 .

The insignificant variance in the observed microstructural patterns of the conical pin welds (between FAT1 and FAT8) and the pinless welds (between P-FAT3 and P-FAT7) necessitated the description of each weld category with one microstructural image. Figures 6,7 show the weld zones of pinless and conical pin welds, respectively. Figures $6 \mathrm{a}, 7 \mathrm{c}$ show the grain morphology of the base metal (BM); no plastic deformation or microstructural alteration occurs in these regions. The stir zones (SZ) of the welds undergo intense plastic deformation, and these zones are exposed to high frictional temperature and stirring/material flow due to the rotating effect of the welding tool. This promotes dynamic recrystallization of the weld region (SZ) and facilitates the inter- 

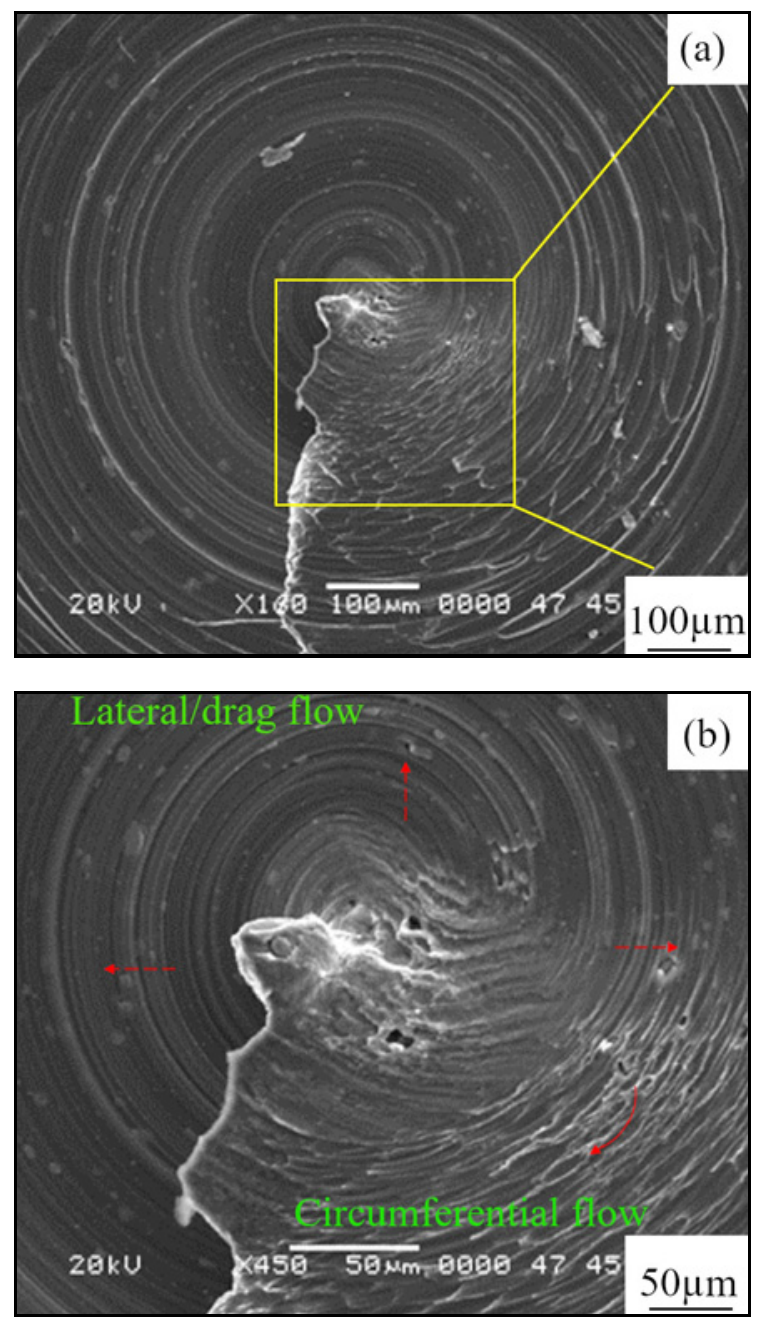

Fig. 5. The surface of pinless weld nugget showing the direction of material flow.

material mixture of the upper and lower sheets [7]. The resultant microstructures or grains of this region are approximately equiaxed, homogeneous, and have an order of magnitude smaller than that of the BM [31].

Figures 6b, 7a show the thermo-mechanical affected regions (TMAZ) of the respective welds. These regions are affected by both the thermal cycle and limited plastic deformation during welding [32, 34]. The grain structures of the welds' TMAZ(s) are highly deformed, and no evidence of uniformly distributed equiaxed grains is present in these regions. On the other hand, the non-deformed heat affected zones (HAZ) of both weld categories are indicated in Figs. 6 and 7 , respectively. The upward flow of material forms hook profile in conical pin welds, and a section of the hook path shows partial bonding of the upper and lower sheets (see Fig. 7b). The bonding progresses towards the hook tip while the degree of inter-material bonding decreases down the hook curve.
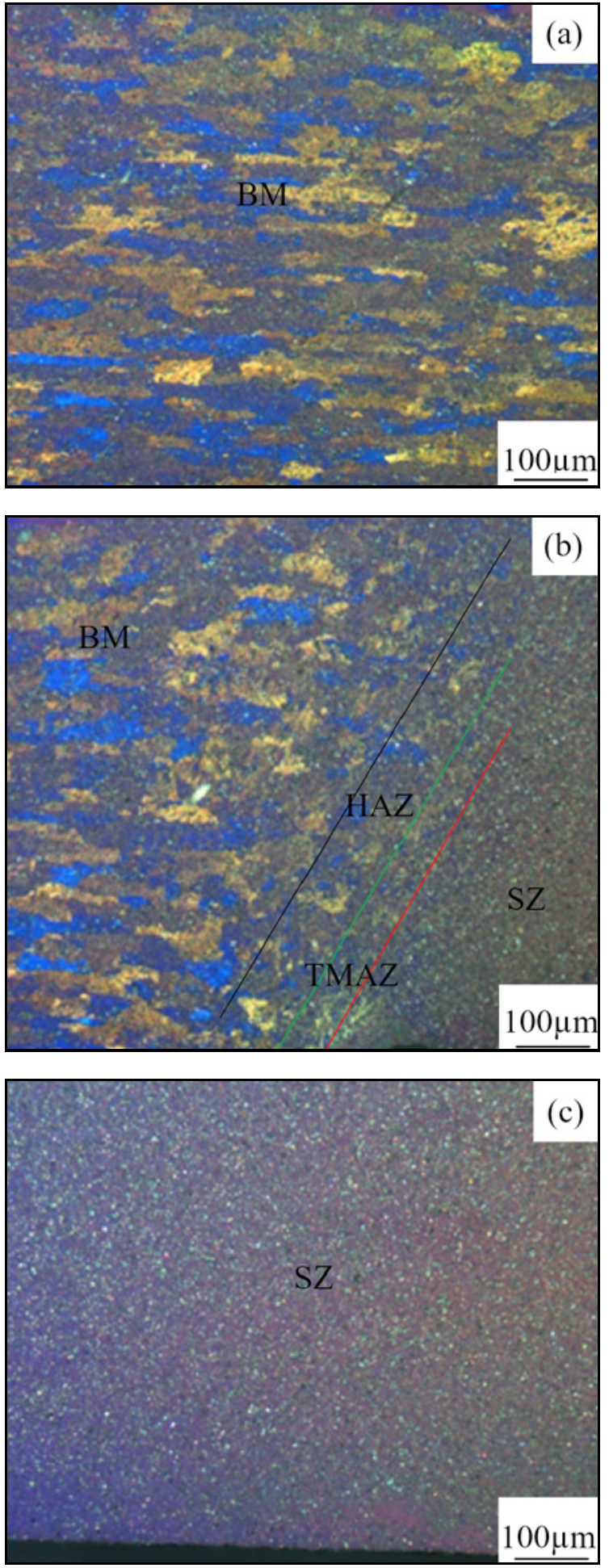

Fig. 6. Weld micrographs of pinless weld: (a) base metal, (b) multiple weld zones (TMAZ, HAZ, BM, SZ), and (c) stir zone (SZ).

\subsection{Hardness}

The micro-indentation hardness $\left(\mathrm{HV}_{0.5}\right)$ profiles across the pinless and conical pin welds are shown in 

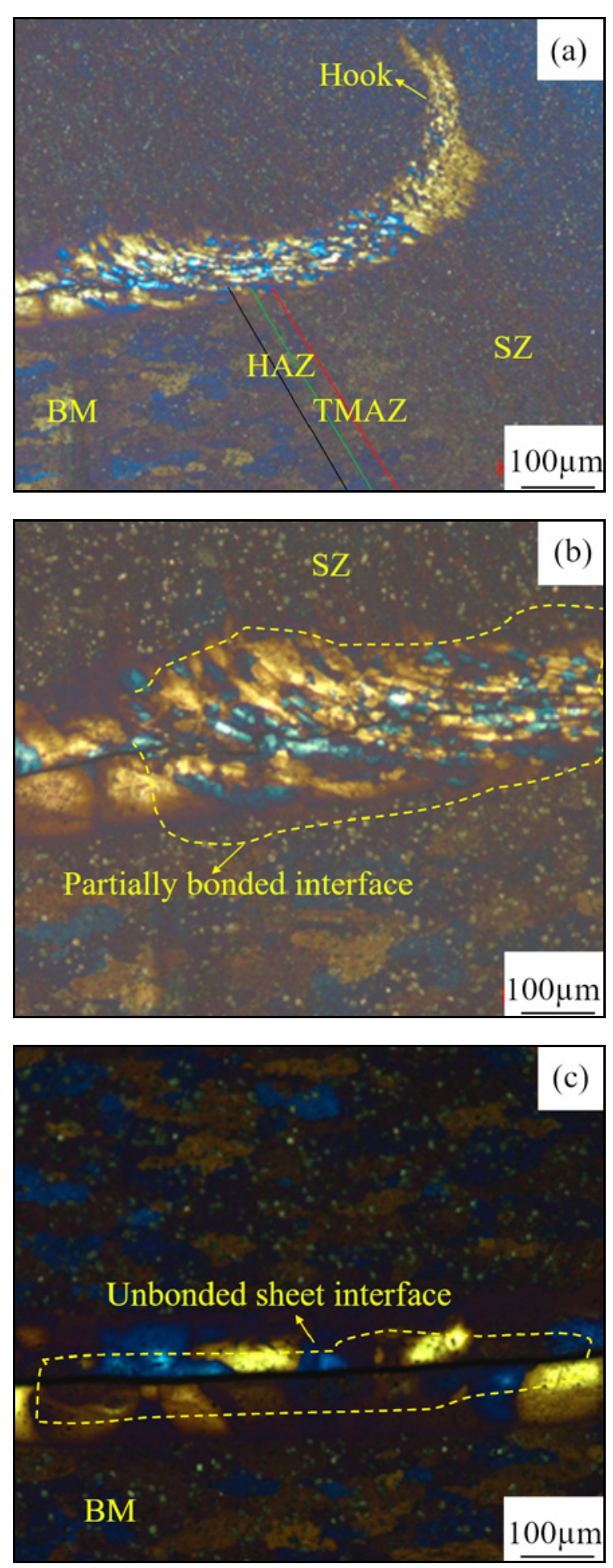

Fig. 7. Weld micrographs of conical pin weld: (a) multiple weld zones with hook profile, (b) partially bonded interface, and (c) unbonded region.

Fig. 8. Maximum hardness values are observed at the interfacial regions between the stir zone (SZ) and the thermo-mechanical affected zone (HAZ) of both categories of welds. The hardness values at the SZ/TMAZ

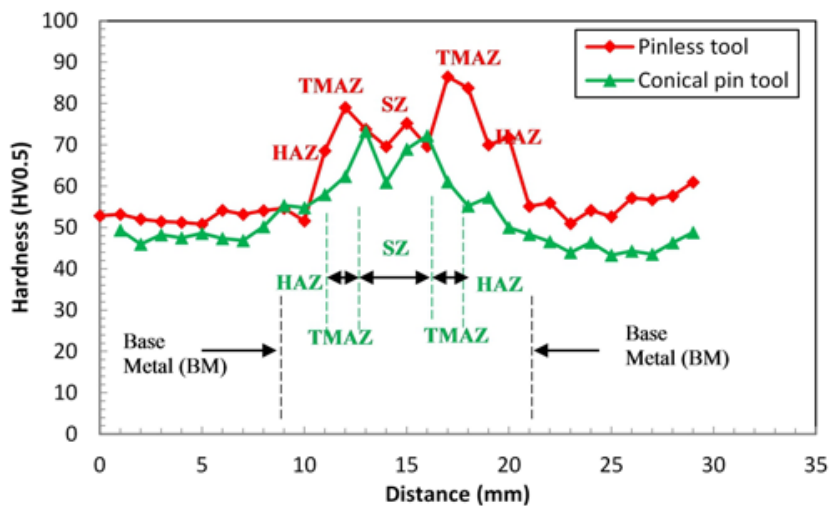

Fig. 8. Vickers microhardness values of welds.

are about 73 and $87 \mathrm{HV}$ in the conical-pin and pinless welds, respectively. However, the hardness of the base metal (BM) lies within 47 to $54 \mathrm{HV}$. The drop in hardness or trough created at the stir zones of the welds could be attributed to severe plastic deformation, recrystallization, and the likely presence of stress-free grains. As such, the emergence of reduced dislocation density at the center of the SZ could have promoted thermal softening at the SZ. Similarly, hardness gradients are present in the regions of HAZ and TMAZ of both welds. This observation is attributed to the narrow HAZ, and TMAZ established in both weld categories. Besel et al. [38] reported that the local hardness distribution across the weld significantly affected the cyclic stress-strain behavior and caused changes in fatigue crack pattern (transgranular and intergranular). Section 3.4 studies this behavior. The change in the tool profile (pinless and conical pin) significantly affects tool-material contact area, generation of frictionally induced heat input and material flow during the FSSW process. This occurrence is adjudged to have caused the observed disparity in hardness values between the joints (produced with pinless and conical pin tools) shown in Fig. 8.

\subsection{Bending fatigue behavior}

Figure 9 shows the $S-N$ curves of the friction stir spot welded AA2219 alloy. The fatigue lives of both pinless and conical pin welded joints progressively reduced with an increase in the cyclic stress (as indicated in Fig. 9). The welded joints absorb plastic deformations (tensile and compressive deformations) and resist failure to an extent before the eventual final failure during the cyclic lateral loading process, as revealed in Fig. 9.

The fatigue results show that the profile of friction stir spot welded joint affects the fatigue life of welds. Maximum fatigue lives of 9478 and 8771 cycles to failure were attained in the conical-pin and pinless welded 


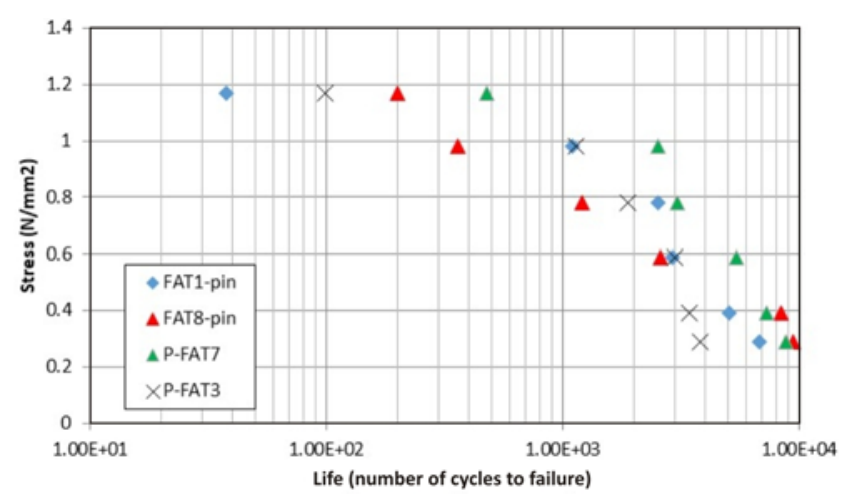

Fig. 9. Comparison of fatigue data of pinless and conical pin welded joints.

joints, respectively. This finding corroborates the assertion of Costa et al. [39] that the fatigue strength of joints is greatly influenced by joint geometry. Despite the presence of probe holes in the conical-pin welds, conical pin weld produces higher fatigue strength under lateral cyclic bending as compared to the pinless welds. The comparison of fatigue behaviors of the joints with and without keyholes was investigated by Rao et al. [40]. It was revealed that the decrease in the true weld length owing to the presence of keyhole and intermetallic compounds lowered the fatigue life of the joints. In the examined experiment, the presence of material flow impelled stress raiser (or microscopic toe-notch) in the region of SZ/TMAZ of the pinless welds is adjudged to have influenced this outcome. Similarly, cyclic hardening [41] could be responsible for the improved fatigue strength in the conical pin weld while the enforced pre-straining at the toe-notch region of the pinless weld could be a major factor in the decreased fatigue strength [42]. Fractography of the failed weld surfaces is carried out to comprehend this result (see Section 3.3).

Welding parameter levels affect the bending/lateral fatigue life of the friction stir spot welded joints of AA2219 aluminum alloys. Improved fatigue strengths are obtained at $1600 \mathrm{rpm}$ in both weld categories (FAT8 and P-FAT7). The variation in tool rotational speeds mainly affects welds' heat input; and conversely, material intermixing and microstructure of weld are affected by the induced heat input. To this extent, favorable weld structure is adjudged to be obtained at $1600 \mathrm{rpm}$ in the pinless and conical pin welds. The reduced fatigue life in pinless welds produced at $1400 \mathrm{rpm}$ could be attributed to the higher shoulder plunge effect and reduced effective sheet thickness (upper sheet).

\subsection{Fractography}

The fracture morphologies of the conical pin and
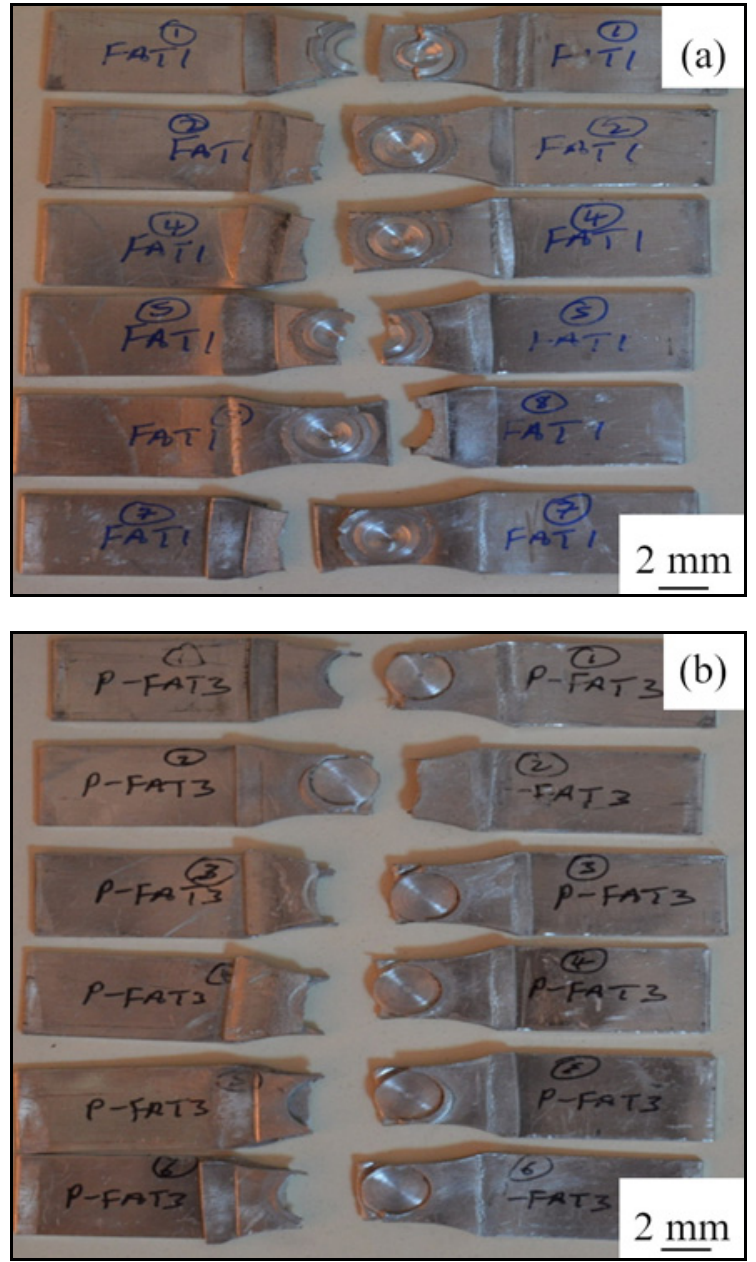

Fig. 10. Fracture modes under bending cyclic loading conditions: (a) conical pin welds and (b) pinless welds.

pinless welded joints subjected to lateral fatigue failures are shown in Fig. 10. The visual assessment of the failed specimens (see Fig. 10) reveals that all the pinless welded samples have the same failure pattern while different failure patterns are observed in the conical pin welded joints. Failure occurs in the regions adjacent to the weld nugget zone (WNZ) in pinless welds whereas failure occurs across the weld nugget and through the HAZ/TMAZ regions of the conical pin welded joints. The difference in the failure patterns of the conical pin welded joint may be attributed to the effect of welding parameters and cyclic stress or cyclic hardening on the joint. Rodriguez et al. [43] reported that all fatigue samples failed at the HAZ/TMAZ region under fully-reversed cyclic loading. However, complex failure paths are observed in the conical pin welds.

The macrographs of fracture surfaces of some selected pinless and conical pin welded joints based on the minimum and maximum fatigue lives as viewed under an optical microscope are shown in Figs. 11 and 

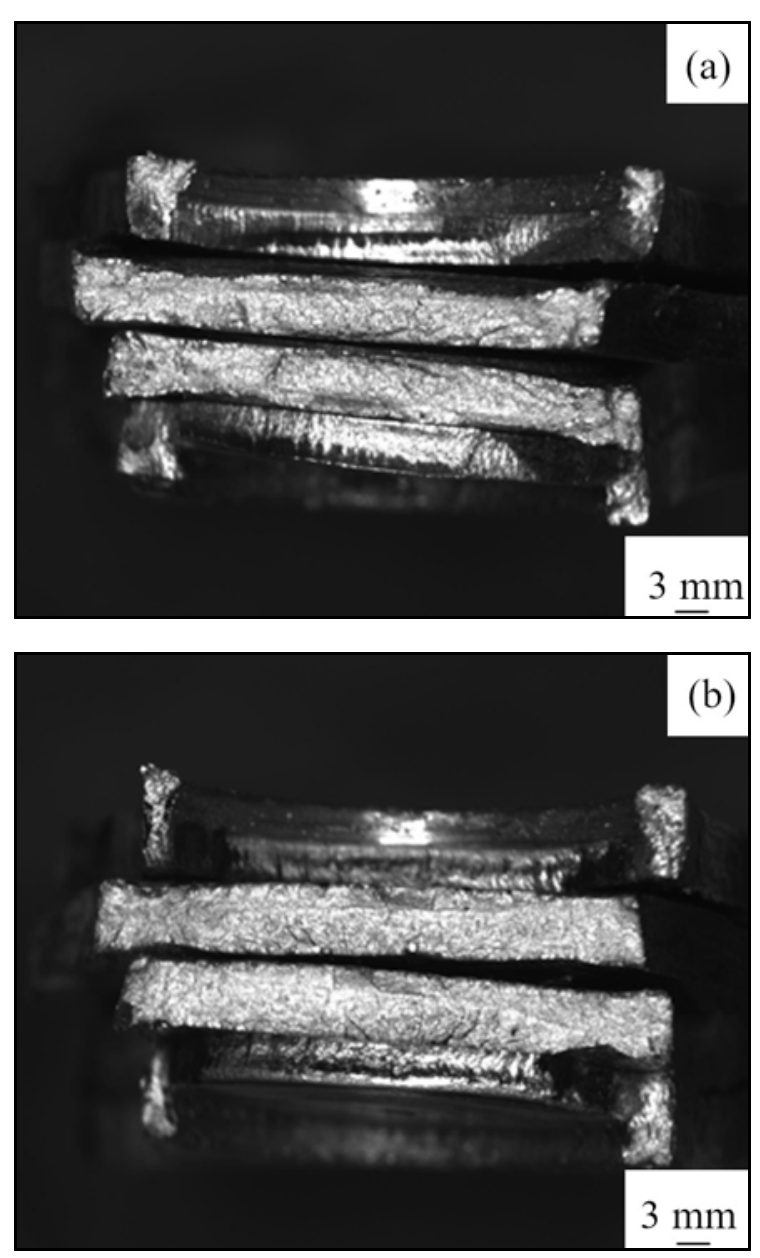

Fig. 11. Fracture surfaces of pinless welds - fracture through the circumferential shoulder plunge area and thickness of the lower plate: (a) P-FAT3 and (b) P-FAT7.

12, respectively. The visual assessment of Fig. 11 provides no significant revelation about the fracture pattern of the welds; the weld surfaces show brittle-like failure modes. On the other hand, Fig. 12a reveals a series of ratchet marks which are confirmation for the occurrence of multiple fracture modes while Fig. 12b shows a distinct multiple crack growth patterns into the weld sample as indicated by the arrows on the macrograph.

The fracture surfaces of the test specimens (shown in Figs. 11 and 12) are carefully examined in a scanning electron microscope to find the mechanisms responsible for the fatigue damage in both the pinless and conical pin welds. The close-up scanning electron micrographs of the fracture surfaces of all welds (conical and pinless welds) show very limited striations. The presence of no visible striations on some regions of the fracture surfaces suggests that unstable fatigue crack growth occurs in these regions during the cyclic lateral loading. This agrees with the findings of Lage et al. [44]. The formed crack striations or concentric
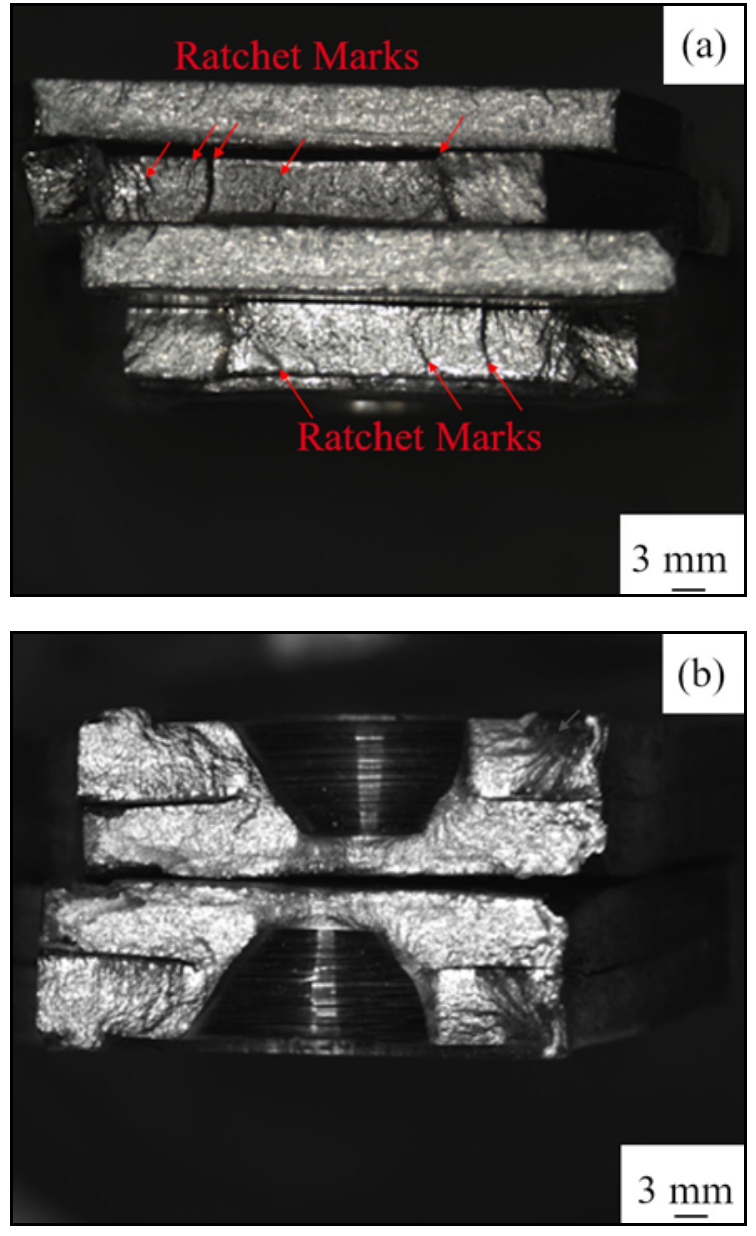

Fig.12. Fracture surfaces of conical pin welds: (a) fracture through sheet thickness in FAT1 sample and (b) fracture through the center of weld in FAT8 sample.

marks on Figs. 11 and 12 were impaired or damaged due to the friction and contact between the cracked faces or relative movement of the two sides of the crack during crack propagation. As a result, the entire striation marks could not be fully seen, but patches of striations were left along the crack propagation path in all the failed pinless and conical pin welded fatigue samples.

The close-up scanning electron micrographs of the pinless fracture surfaces reveal similar failure pattern (see Fig. 10b). As a result, Fig. 13 alone is utilized in clarifying the failure mechanism of the pinless welds subjected to fatigue loading. SEM micrographs were taken from the fracture surface of the upper sheet as indicated in Fig. 13a and the high magnification regions of this fracture surface (marked as B, C, and D) were presented in Figs. 13b-d. Figure 13b is the region close to the SZ/TMAZ of the pinless weld around the circumferential edge of the SZ in the upper sheet. This region is characterized by layers of striation marks, and this is an indication that multiple fractures oc- 

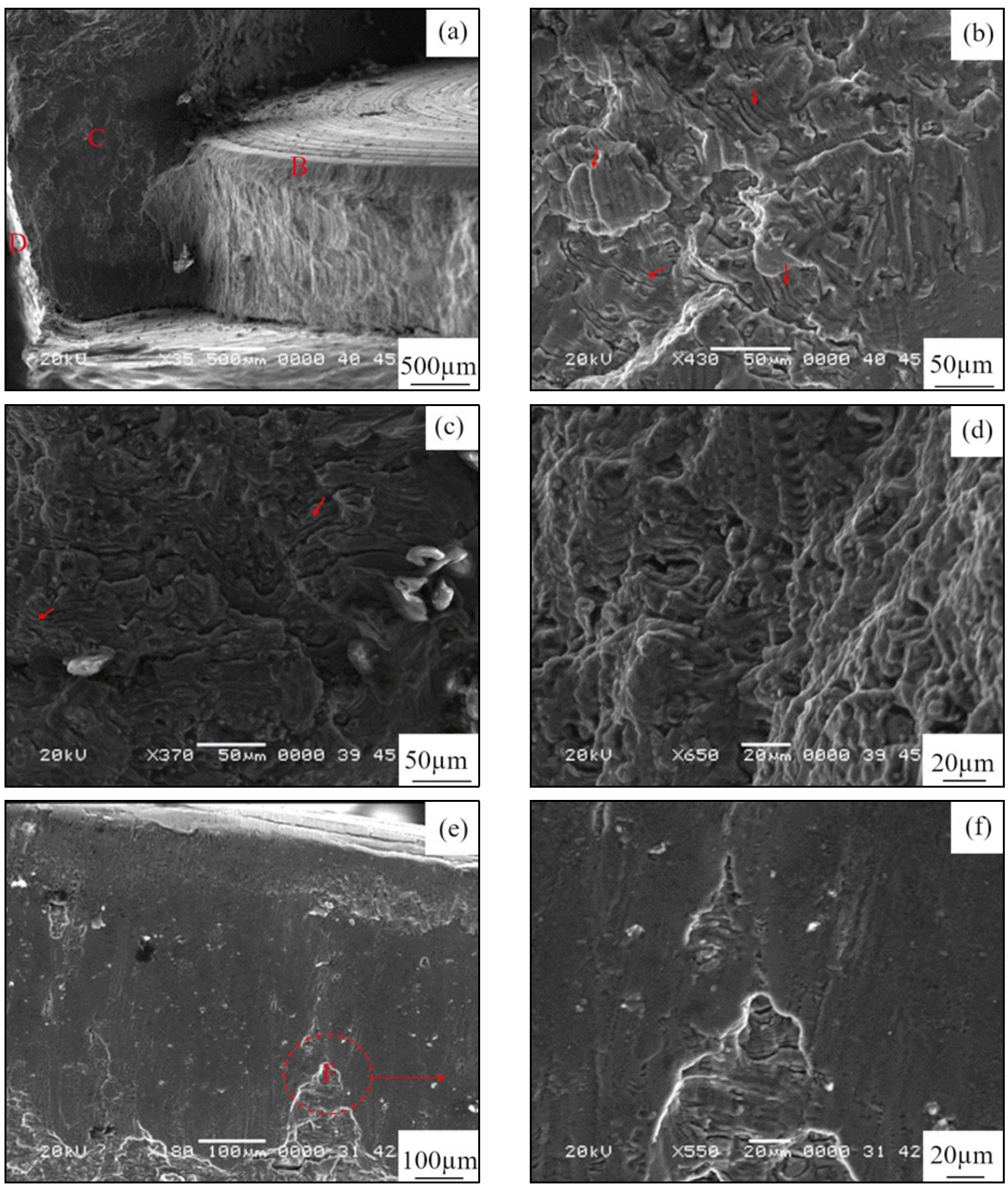

Fig. 13. Scanning electron micrographs of the fracture surface of pinless welded fatigue specimen: (a) morphology of failure, (b) region of crack growth, (c) and (d) regions of final failure showing tensile dimples, (e) fracture surface of the lower sheet, and (f) magnified view of lower sheet fracture.

cur. The concentricity of the striation mark shows that crack propagates from the top area of the SZ/TMAZ into the thickness of the upper sheet while other concentric marks indicate crack propagation along the width of the upper sheet. Figure 13c shows fatigue striations with irregular spread out or direction, and this form of occurrence has been reported to occur due to a change in local stress state [32]. Consequently, no significant fracture mechanism can be drawn from this region. On the other hand, Fig. 13d appears to be the final failure appearance of the pinless welds as ductile fracture/failure mode in the form of fibrous-like, elongated and irregular ductile dimples are observed. The elongated dimples indicate that ductile shearing 
overload occurs at the final stages of fracture during bending fatigue loading of the pinless welds. In the same manner, the SEM micrographs from the fracture surface of the lower sheet were taken, as shown in Figs. 13e,f. Large sections of this fracture surface show no evidence of striation but smeared, and smooth outlooks are present. The little striation marks of this region (see Fig. 13f) are not sufficient in describing the fracture mode through the lower sheet of the pinless weld.

It can be deduced that grain refinement (dynamically recrystallized region) inhibits crack propagation in pinless welded joints as the crack propagation path occurs outside the SZ. The microstructure of pinless weld influences crack propagation, and failure occurs through the region with the highest microhardness value. The material flow induced toe-notch in the SZ/TMAZ of pinless welds significantly influences the failure mechanism of pinless welds. The welding property that has the most dominant effect on fatigue crack cannot be well identified among microstructure, microhardness, and toe-notch effect. Multiple fracture modes through the upper sheet (owing to induced toenotch) and the lower sheet owing to the tensile and compressive loading effects on the pinless welds are adjudged to be responsible for the reduced fatigue life of pinless welds as compared to that of conical pin welded joints.

SEM micrographs were taken from the fracture surface of the conical pin welded FAT1 joint, as indicated in Fig. 14. Under dynamic loading condition, the dominant weld failure did not occur at the hook tip of the weld, as shown in Figs. 14a,b. The extension of the welded region was more sensitive to shearing rather than the hook morphology in the works of Lage et al. [44] owing to the reduced tool penetration depth in the pin assisted welds. The hook tip produced two forms of crack growth $\left(\mathrm{P}_{1}\right.$ and $\mathrm{P}_{2}$, as indicated in Fig. 14b) due to the compressive and tensile loading effects on the weld. $\mathrm{P}_{1}$ and $\mathrm{P}_{2}$ were not the regions with the most stress concentrations; as a result, further crack growth could not be achieved. It could be adjudged that the refined or recrystallized grains of the stir zone of the welds inhibited the growth of $\mathrm{P}_{1}$ and $\mathrm{P}_{2}$. From one end of the fracture surface, as shown in Fig. 14c, fracture paths are obvious, and they are indicated by the red arrows. This is evidence of multiple crack propagation. The magnified view of this region (D) is given in Fig. 14d. Elongated hair-like multiple crack growth structures progressing into the recrystallized region of the weld and the thickness of the upper sheet are present. From the other end of the fracture surface, as shown in Fig. 14e, the magnified view of region $\mathrm{F}$ produces Fig. 14f and further magnification of region G (in Fig. 14f) produces Fig. 14g. Evidence of fatigue striations is observed in this region. It shows that fatigue crack commences from the base of the expelled flash on the surface of the weld and propagates into the adjacent region of the weld's stir zone. The crack progresses into the refined or dynamically recrystallized grains of the stir zone. The ultimate failure occurs at the lower sheet (at the region below the pin cavity) as smashed dimple fractures are present as shown in Fig. 14h. Thus, microstructure and hardness characteristics of weld have no significant effects on the fatigue fracture mode of FAT1. Minimization of inherent nugget defects and extruded flash can improve the lateral fatigue life of the joints.

The close-up scanning electron micrograph (fracture surfaces) of the conical pin welded FAT8 joint is shown in Fig. 15. Figure 15a shows the edge view of the fracture surface, and the magnification of region $\mathrm{B}$ on it is given in Fig. 15b. Minute fatigue striations are present on the micrograph owing to the contact of the crack faces during loading. Dotted lines on the micrograph enclose evidence of multiple crack propagation/zones, and this may be due to changes in local stress state during cyclic loading. Assessment of the adjacent region of Fig. $15 \mathrm{~b}$ is conversely examined as Fig. 15c. Region D on Fig. 15c is magnified, and its micrograph is given in Fig. 15d. Mixed fatigue striations are also present on the close-up micrograph. The actual crack nucleation site based on the micrograph (see Fig. 15d) is difficult to identify, but evidence of through-thickness crack propagation can be deduced from this view. The other edge of the fracture surface reveals more pronounced fatigue striations, as shown in Fig. 15g (Fig. 15g is the magnified view of Figs. 15e,f). The damaged surface is present in this view (see Figs. 15e,f) and this could have been caused by a change in failure mechanism during the cyclic loading process. Afterward, notable fatigue striations are present, and this is a confirmation that cracks nucleation site is located somewhere close to the surface of the sheet. The final fracture surface of the weld showed irregular ductile dimples, as shown in Fig. 15h. Conclusively, complex fatigue failure occurs in FAT8, and this has been supported by the preliminary visual assessment shown in Fig. 12a. The presence of ratchet marks on the fracture surface (see Fig. 12a) indicates multiple fine fatigue initiation sites, and this makes the identification of the actual and dominant crack site to be difficult. Based on this surface appearance, the significant role of hardness and microstructure on the fatigue crack behavior of FAT8 joints cannot be clarified.

\section{Conclusions}

Bending fatigue behavior of spot welds with different morphologies owing to the profiles of the welding tool has been investigated. The microstructural assessment of the weld structure reveals homogeneity of 

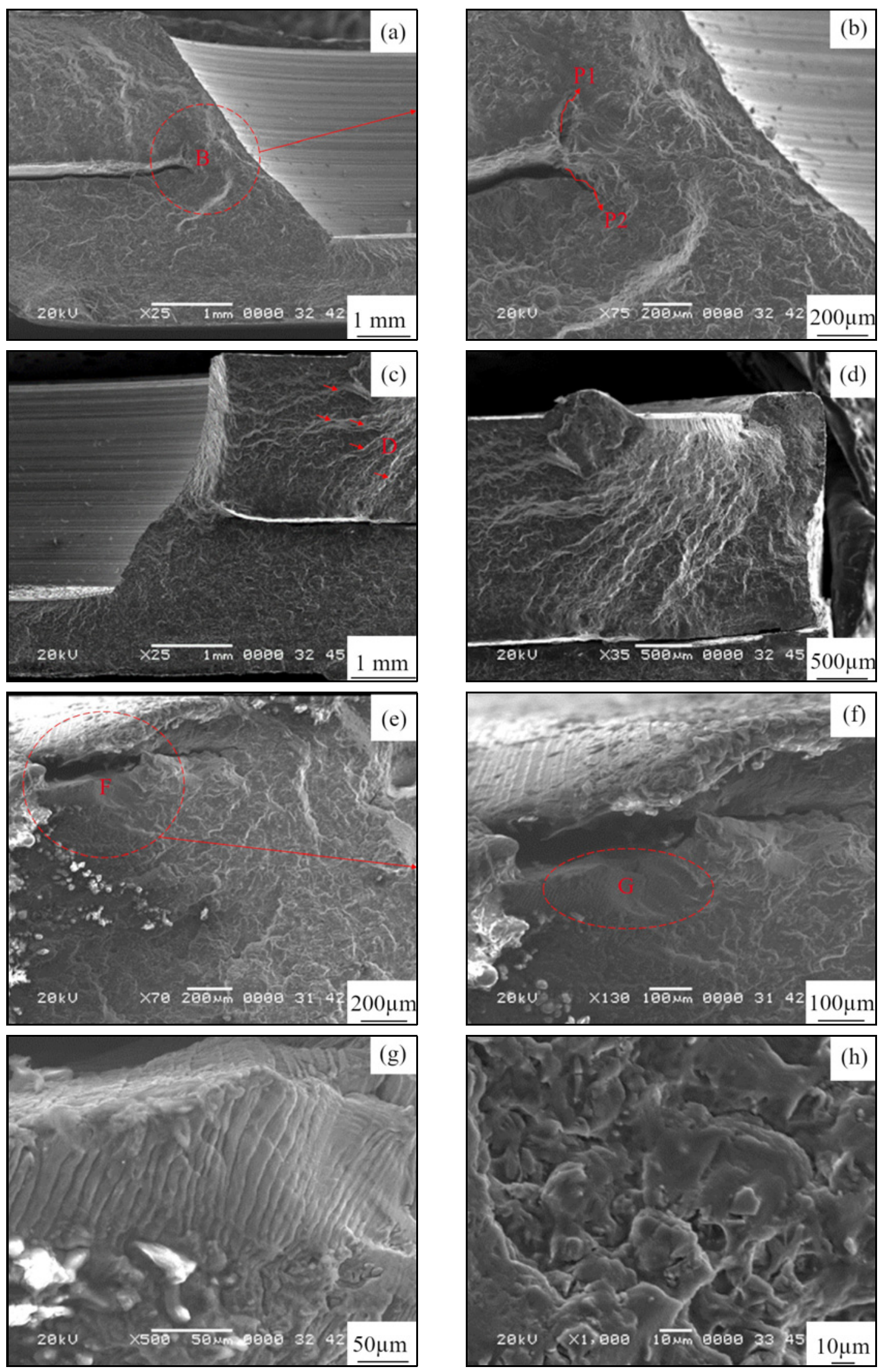

Fig. 14. Scanning electron macrographs of the fracture surface of conical pin welded fatigue specimen (FAT1 specimen): (a) hook effect on fracture, (b) magnified hook effect on fracture, (c) right end view of fracture surface, (d) magnified right end view, (e) and (f) are left end views of fracture surface, (g) magnified left end view, and (h) final failure. 

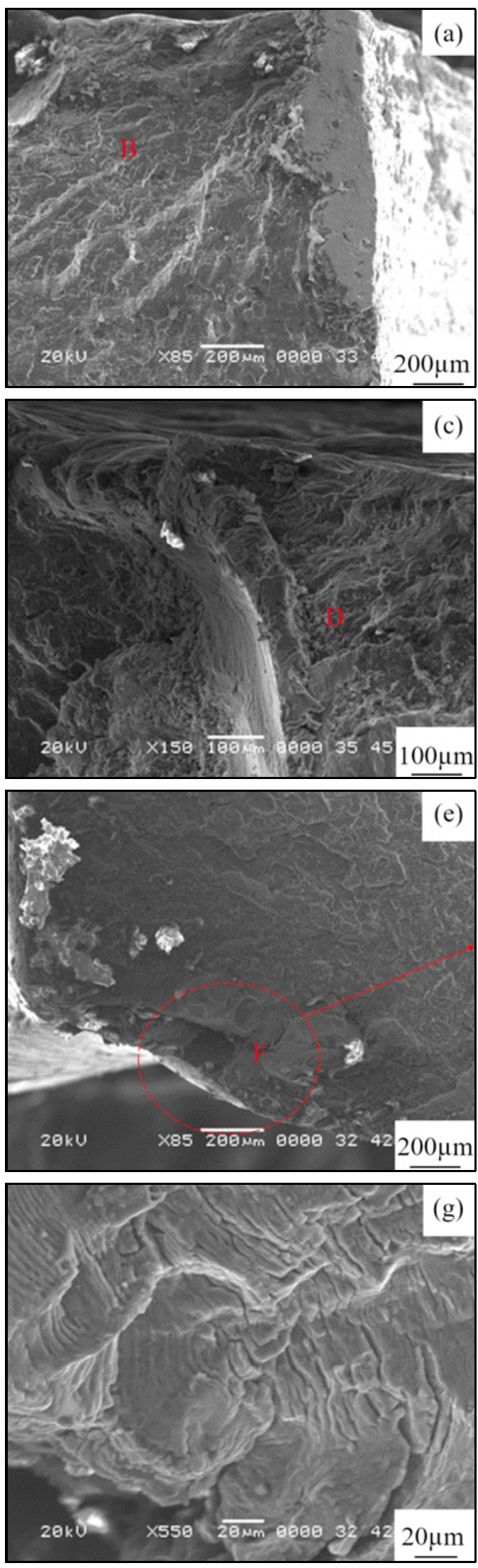
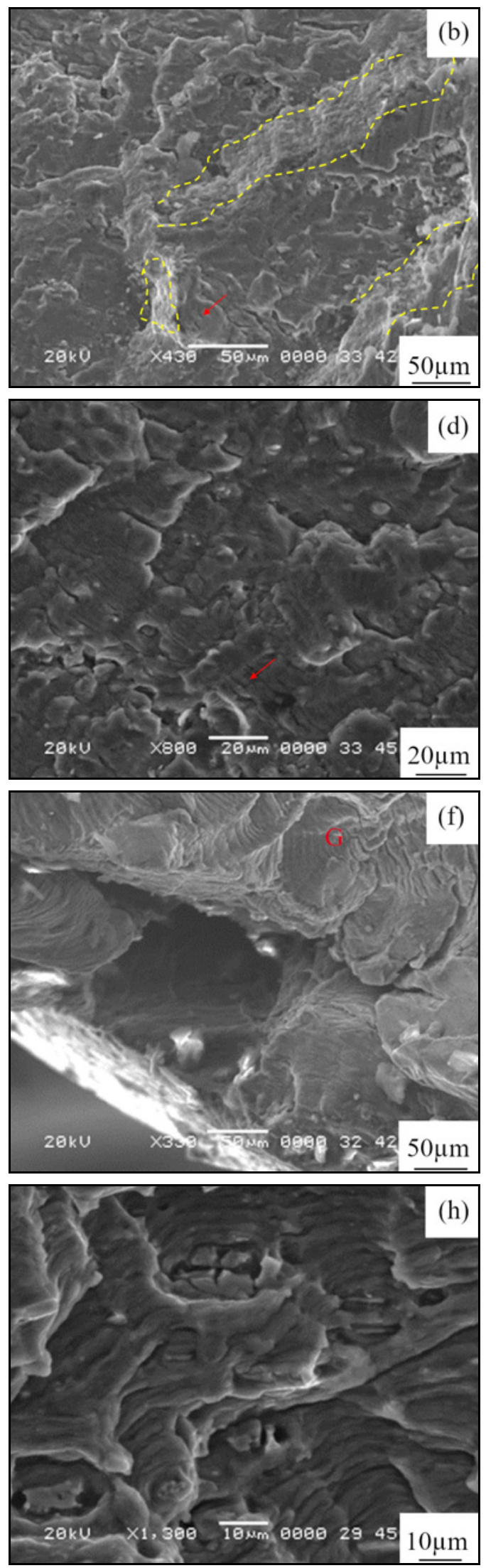

(h)

Fig. 15. Scanning electron macrographs of the fracture surface of conical pin welded fatigue specimen (FAT8 specimen): (a) end view of fracture surface, (b) magnified end view of (a), (c) adjacent view of region (a), (d) magnified adjacent view of region (a), (e) and (f) other end view of fracture surface, (g) magnified end view of (f), and (h) final failure. 
fine recrystallized grains at the stir zone while inhomogeneous structure occurs in other weld regions. The following findings are obtained:

1. Outstretching material flow towards the shoulder edge of the pinless tool establishes a microscopic toe-notch at the SZ/TMAZ while hook defects are present in the conical pin welded joint.

2. The root of expelled flash contributes to the complex fracture mode of conical pin welds while the flash base does not influence the fracture morphology of pinless welds.

3. Grain refinement, microhardness, and microscopic toe-notch affect the fatigue failure of pinless welds. Crack propagation around the circumferential edge of the weld nugget zone (SZ/TMAZ region) is the fracture mode of the pinless welded joint.

4. Complex fracture morphology ensues in the weld zone of the conical pin joints under lateral cyclic loading. Crack propagation across the weld nugget zone and failure through the sheet thickness are the two fracture modes observed in conical pin welds.

5. Cyclic stress level and welding parameter level affect the fracture morphology of the conical pin welded joints subjected to lateral dynamic loading.

\section{Acknowledgements}

The authors would like to acknowledge the support of Mr. Onur Birbasar of the R \& D Department of Assan Aluminium, Istanbul, Turkey. This work was also supported by a grant from the Scientific Research Project Unit (BAP) of Kocaeli University (grant NO. 2015/71HD), Turkey.

\section{References}

[1] Wahid, M. A., Khan, Z. A., Siddiquee, A. N., Shandley, R., Sharma, N.: Proc. IMechE Part B: J. Eng. Manuf., 233, 2018, p. 1700. doi: $10.1177 / 0954405418789982$

[2] Wahid, M. A., Khan, Z. A., Siddiquee, A. N.: Trans. Nonferrous Met. Soc. China, 28, 2018, p. 193. doi:10.1016/s1003-6326(18)64653-9

[3] Ojo, O. O., Taban, E., Kaluc, E.: J. Mater. Process. Technol., 251, 2018, p. 118. doi:10.1016/j.jmatprotec.2017.08.026

[4] Rouzbehani, R., Kokabi, A. H., Sabet, H., Paidar, M., Ojo, O. O.: J. Adv. Manuf. Technol., 262, 2018, p. 239. doi:10.1016/j.jmatprotec.2018.06.033

[5] Wahid, M. A., Siddiquee, A. N., Khan, Z. A., Sharma, N.: Mater. Res. Express, 5, 2018, p. 1. doi:10.1088/2053-1591/aab8e3

[6] Ebrahimzadeh, V., Paidar, M., Safarkhanian, M. A., Ojo, O. O.: Inter. J. Adv. Manuf. Technol., 96, 2018, p. 1237. doi:10.1007/s00170-018-1679-5

[7] Chowdhury, S. H., Chen, D. L., Bhole, S. D., Cao, X., Wanjara, P.: Mater. Sci. Eng. A, 556, 2012, p. 500. doi:10.1016/j.msea.2012.07.019
[8] Karthikeyan, R., Balasubramanian, V.: Exp. Techniques, 37, 2011, p. 6. doi:10.1111/j.1747-1567.2011.00746.x

[9] Plaine, A. H., Suhuddin, U. F. H., Alcantara, N. G., Dos Santos, J. F.: Int. J. Fatigue, 91, 2016, p. 149. doi:10.1016/j.ijfatigue.2016.06.005

[10] Oladimeji, O. O., Taban, E.: Weld World, 60, 2016, p. 415. doi:10.1007/s40194-016-0317-9

[11] Xu, W. F., Liu, J. H., Chen, D. L., Luan, G. H.: Int. J. Adv. Manuf. Technol., 74, 2014, p. 209. doi:10.1007/s00170-014-5988-Z

[12] Susmel, L., Hattingh, D. G., James, M. N., Tovo, R.: Int. J. Fatigue, 10, 2016, p. 207. doi:10.1016/j.ijfatigue.2016.08.010

[13] Boni, L., Lanciotti, A., Polese, C.: Int. J. Fatigue, 80, 2015, p. 238. doi:10.1016/i.iifatigue.2015.06.010

[14] Das, H., Chakraborty, D., Pal, T. K.: Trans. Nonferrous Met. Soc. China, 24, 2014, p. 648. doi:10.1016/s1003-6326(14)63107-1

[15] Uematsu, Y., Tokaji, K., Shibata, H., Tozaki, Y., Ohmune, T.: Int. J. Fatigue, 31, 2009, p. 1443. doi:10.1016/j.ijfatigue.2009.06.015

[16] Hassanifard, S., Ahmadi, S. R., Pour, M. M.: Mater. Design, 44, 2013, p. 291. doi:10.1016/j.matdes.2012.06.055

[17] Venukumar, S., Muthukumaran, S., Yalagi, S. G., Kailas, S. V.: Int. J. Fatigue, 61, 2014, p. 93. doi:10.1016/i.ijfatigue.2013.12.009

[18] Lin, P. C., Pan, J., Pan, T.: Int. J. Fatigue, 30, 2008, p. 74. doi:10.1016/j.ijfatigue.2007.02.016

[19] Tran, V. X., Pan, J., Pan, T.: Int. J. Fatigue, 32, 2010, p. 1022. doi:10.1016/j.ijfatigue.2009.11.009

[20] Tran, V. X., Pan, J., Pan, T.: Int. J. Fatigue, 30, 2008, p. 2175. doi:10.1016/j.ijfatigue.2008.05.025

[21] Uematsu, Y., Tokaji, K., Tozaki, Y., Kurita, T., Murata, S.: Int. J. Fatigue, 30, 2008, p. 1956. doi:10.1016/j.ijfatigue.2008.01.006

[22] Tu, S. T., Zhang, X. C.: Fatigue Crack Initiation Mechanisms. In: Reference Module in Materials Science and Materials Engineering. Amsterdam, Elsevier Inc. 2016. doi:10.1016/B978-0-12-803581-8.02852-6

[23] Lin, P. C., Su, Z. M., He, R. Y., Lin, Z. L.: Int. J. Fatigue, 38, 2012, p. 25. doi:10.1016/j.ijfatigue.2011.11.003

[24] Su, Z. M., He, R. Y., Lin, P. C., Dong, K.: J. Mater. Process. Technol., 236, 2016, p. 162. doi:10.1016/j.jmatprotec.2016.05.014

[25] Wang, D. A., Chen, C. H.: J. Mater. Process. Technol., 209, 2009, p. 367. doi:10.1016/i.jmatprotec.2008.02.008

[26] Tran, V. X., Pan, J.: Int. J. Fatigue, 32, 2010, p. 1167. doi:10.1016/j.ijfatigue.2009.12.011

[27] Ibrahim, I., Uematsu, Y., Kakiuchi, T., Tozaki, Y., Mizutani, Y.: Sci. Technol. Weld. Joi., 20, 2015, p. 670. doi:10.1179/1362171815Y.0000000053

[28] Ojo, O. O., Taban, E., Kaluc, E.: Mater. Design, 108, 2016, p. 518. doi:10.1016/i.matdes.2016.07.013

[29] Shen, Z., Chen, Y., Hou, J. S. C., Yang, X., Gerlich, A. P.: Sci. Technol. Weld. Joi., 20, 2015, p. 48. doi: $10.1179 / 1362171814 \mathrm{y} .0000000253$

[30] Choi, D., Ahn, B., Lee, C., Yeon, Y., Song, K., Jung, S.: Mater. Trans., 51, 2010, p. 1028. doi:10.2320/matertrans.m2009405 
[31] Ojo, O. O., Taban, E., Kaluc, E.: Mater. Test., 57, 2015, p. 609. doi:10.3139/120.110752

[32] Effertz, P. S., Infante, V., Quintino, L., Suhuddin, U., Hanke, S., dos Santos, J. F.: Int. J. Fatigue, 87, 2016, p. 381. doi:10.1016/j.ijfatigue.2016.02.030

[33] Rao, H. M., Jordon, J. B., Barkey, M. E., Guo, Y. B., $\mathrm{Su}, \mathrm{X}$., Badarinarayan, H.: Mater. Sci. Eng. A, 564, 2013, p. 369. doi:10.1016/j.msea.2012.11.076

[34] Rosendo, T., Parra, B., Tier, M. A. D., da Silva, A. A. M., dos Santos, J. F., Strohaecker, T. R., Alcantara, N. G.: Mater. Design, 32, 2011, p. 1094. doi:10.1016/j.matdes.2010.11.017

[35] Ojo, O. O., Taban, E.: Sādhanā, 43, 2018, p. 1. doi:10.1007/s12046-018-0882-2

[36] Ojo, O. O., Taban, E., Kaluc, E.: Mater. Test., 60, 2018, p. 979. doi:10.3139/120.111245

[37] Guo, S., Shah, L., Ranjan, R., Walbridge, S., Gerlich, A.: Int. J. Fatigue, 118, 2019, p. 150. doi:10.1016/j.ijfatigue.2018.09.004

[38] Besel, Y., Besel, M., Mercado, U. A., Kakiuchi, T., Hirata, T., Uematsu, Y.: Int. J. Fatigue, 99, 2017, p. 151. doi:10.1016/j.ijfatigue.2017.02.024
[39] Costa, M. I., Leitao, C., Rodrigues, D. M.: J. Mater. Process. Technol., 250, 2017, p. 289. doi:10.1016/j.jmatprotec.2017.07.030

[40] Rao, H. M., Jordon, J. B., Boorgu, S. K., Kang, H., Yuan, W., Su, X.: Int. J. Fatigue, 105, 2017, p. 16. doi:10.1016/j.ijfatigue.2017.08.012

[41] Sillapasa, K., Surapunt, S., Miyashita, Y., Mutoh, Y., Seo, N.: Int. J. Fatigue, 63, 2014, p. 162. doi:10.1016/i.ijfatigue.2014.01.021

[42] White, B. C., White, R. E., Jordon, J. B., Allison, P. G., Rushing, T., Garcia, L.: Mat Sci. Eng. A, 736, 2018, p. 228. doi:10.1016/j.msea.2018.08.104

[43] Rodriguez, R. I., Jordon, J. B., Allison, P. G., Rushing, T., Garcia, L.: Mat. Sci. Eng. A, 654, 2016, p. 236. doi:10.1016/j.msea.2015.11.075

[44] Lage, S. B. M., Campanelli, L. C., de Bribean Guerra, A. P., Shen, J., dos Santos, J. F., Pereira da Silva, P. S. C., Bolfarini, C.: Int. J. Adv. Manuf. Tech., 100, 2018, p. 101. doi:10.1007/s00170-018-2696-0 